\title{
PFOS induces proliferation, cell-cycle progression, and malignant phenotype in human breast epithelial cells
}

\author{
Paula Pierozan $^{1} \cdot$ Oskar Karlsson $^{1}$
}

Received: 17 June 2017 / Accepted: 21 September 2017 / Published online: 23 October 2017

(C) The Author(s) 2017. This article is an open access publication

\begin{abstract}
Perfluorooctanesulfonic acid (PFOS) is a synthetic fluorosurfactant widely used in the industry and a prominent environmental toxicant. PFOS is persistent, bioaccumulative, and toxic to mammalian species. Growing evidence suggests that PFOS has the potential to interfere with estrogen homeostasis, posing a risk of endocrine-disrupting effects. Recently, concerns about a potential link between PFOS and breast cancer have been raised, but the mechanisms underlying its actions as a potential carcinogen are unknown. By utilizing cell proliferation assays, flow cytometry, immunocytochemistry, and cell migration/invasion assays, we examined the potentially tumorigenic activity of PFOS (100 nM-1 mM) in MCF-10A breast cell line. The results showed that the growth of MCF-10A cells exposed to 1 and $10 \mu \mathrm{M}$ PFOS was higher compared to that of the control. Mechanistic studies using $10 \mu \mathrm{M}$ PFOS demonstrated that the compound promotes $\mathrm{MCF}-10 \mathrm{~A}$ proliferation through accelerating $\mathrm{G}_{0} / \mathrm{G}_{1-}$ to-S phase transition of the cell cycle after 24,48 , and 72 h of treatment. In addition, PFOS exposure increased CDK4 and decreased p27, p21, and p53 levels in the cells. Importantly, treatment with $10 \mu \mathrm{M}$ PFOS for $72 \mathrm{~h}$ also stimulated MCF-10A cell migration and invasion, illustrating its capability to induce neoplastic transformation of human breast epithelial cells. Our experimental results suggest that exposure to low levels of PFOS might be a potential risk factor in human breast cancer initiation and development.
\end{abstract}

Oskar Karlsson

Oskar.Karlsson@farmbio.uu.se

1 Department of Pharmaceutical Biosciences, Uppsala University, Uppsala, Sweden
Keywords Perfluorooctanesulfonic acid - MCF-10A cells $\cdot$ Breast cancer $\cdot$ Cell transformation, CDK4, p53

\section{Introduction}

Perfluorooctanesulfonic acid (PFOS), is a man-made fluorosurfactant that has been used as lubricant, component of polishes, paints, paper, textile coatings, food packaging, and fire-retardant foams (Lindstrom et al. 2011). PFOS and PFOS-containing products are released to the environment, contaminating soil, sediment, sludge, and water (Boulanger et al. 2005; Skutlarek et al. 2006). Due to its water solubility and resistance to biological degradation, PFOS is mobilized and released from landfills in water bodies, and bio-accumulates in food chains (Giesy et al. 2001; Parsons et al. 2008). Humans are exposed to PFOS via oral, inhalation, and dermal routes. Studies report that, for the general population, ingestion of fish and drinking water are the main sources of PFOS exposure. Bioaccumulation occurs in humans, leading to a half-life of 5.4 years in serum (Olsen et al. 2007). PFOS are detected in concentrations of up to $48 \mathrm{ng} / \mathrm{ml}$ in human samples such as serum and breast milk, depending on the country and dietary intake (Karrman et al. 2007; Sundstrom et al. 2011). PFOS exposure can result in a variety of toxic effects, including liver toxicity, developmental toxicity, and immunotoxicity (Chang et al. 2008; Saikat et al. 2013). Adverse effects on reproductive organs have also been reported (Saikat et al. 2013). In addition, PFOS is suspected to be an endocrine disruptor with estrogenic activity (Jensen and Leffers 2008), and may contribute to the risk of breast cancer (Bonefeld-Jorgensen et al. 2011), but the potential for PFOS to contribute to endocrine disruption in mammalians is not well defined. 
Hormonally active chemicals, referred to as endocrine disruptors, may be implicated in breast cancer etiology through promotional mechanisms, as well as by affecting mammary gland development (Kortenkamp 2006). Among them, both estrogens and non-estrogenic endocrine disruptors are considered to play critical roles in human breast carcinogenesis (Brody et al. 2007). As a result, investigation of hormonally active compounds in commercial products and pollution is a priority.

Several studies have reported that exposure to PFOS may induce cancer development (Gallo et al. 2012; Olsen et al. 1999, 2007). For example, a case-control study in the Greenland Inuit population revealed an increased breast cancer risk in relation to the level of serum PFOS (Bonefeld-Jorgensen et al. 2011). Moreover, PFOS is suspected to have estrogenic activity and in vitro studies showed that PFOS might have the ability to interact with estrogen receptors (ER)- $\alpha$ and $E R \beta$ and enhance ER-dependent transcriptional activation (Benninghoff et al. 2011; Du et al. 2013; Kjeldsen and Bonefeld-Jorgensen 2013). However, others have reported contradictory data on its estrogenicity and the potential for PFOS to contribute to breast cancer is not well studied (Ishibashi et al. 2007; Maras et al. 2006).

The possible mechanisms by which PFOS may affect the breast tissue can be assessed by animal and cell models. MCF$10 \mathrm{~A}$ is a subline of the spontaneously immortalized human breast epithelial line that is derived from human fibrocystic mammary tissue, with characteristics of normal breast epithelium (Soule et al. 1990). These characteristics make the MCF$10 \mathrm{~A}$ a valuable in vitro model for studying normal breast cell function and the potential of external factors to induce tumor transformation.

In the present study, we investigated the effects of PFOS exposure in the human normal breast epithelial cell line, $\mathrm{MCF}$ $10 \mathrm{~A}$, at various concentrations (100 $\mathrm{nM}-1 \mathrm{mM})$ and different time points (24, 48 and $72 \mathrm{~h}$ ). Cell viability, cell counting, and cell-cycle analysis were applied to investigate the effects of PFOS on cell proliferation. The differential expression of important cell-cycle regulatory proteins was also analyzed and a transwell assay was used to evaluate PFOS-induced cell migration and cell invasion capability. Finally, the effect of PFOS on ER activation and ER $\alpha$ and $E R \beta$ protein expression was evaluated. This study will help to provide insight into the mechanisms involved in human toxicity of PFOS in breast cells and its involvement in breast cancer.

\section{Materials and methods}

\section{Chemicals}

Dimethylsufoxide (DMSO), pharaformaldehyde, 4',6-diamidino-2-phenylindole dihydrochloride (DAPI),
Triton X-100, Propidium iodide (PI), DNAse-free RNAse A, Perfluorooctanesulfonic acid potassium salt (PFOS), cholera toxin (CT), insulin, epidermal growth factor (EGF), and hydrocortisone were obtained from SigmaAldrich (St Louis, MO, USA). Horse serum, penicillin-streptomycin (P/S), Dulbecco's Phosphate-Buffered Saline (PBS), Dulbecco's Modified Eagle's Medium (DMEM), and trypsin solution $(0.05 \%)$ were obtained from Gibco (Invitrogen, Paisley, UK). p53 monoclonal (DO-7), CDK6 monoclonal (75B9), CDK4 monoclonal (DCS-31), and p21 monoclonal (R.229.6) antibodies were obtained from ThermoFisher Scientific (Rockford, IL, USA). P27 Kip1 (D69C12) and Cyclin D1 (92G2) antibodies were obtained from Cell Signaling (Danvers, MA, USA). The secondary antibodies alexa-fluor 555 goat antimouse IgG or 488 goat anti-rabbit IgG, and the blocking agent (normal goat serum) were obtained from Molecular Probes, Invitrogen. Matrigel Basement Membrane Matrix was obtained from Corning (New York, NY, USA). ER $\alpha$ (sc-8002) and $\operatorname{ER} \beta$ (sc-8974) monoclonal antibodies were obtained from Santa Cruz Biotechnology (Bergheimer, HD, DE). ICI 182,780 was obtained from Tocris Bioscience (Avonmouth, Bristol, UK).

\section{Cell culture}

MCF-10A cells were obtained as frozen vials from the American Type Culture Collection (ATCC, Manassas, VA, USA). Cells were maintained as a monolayer in $10 \mathrm{~cm}^{2}$ tissue-culture plastic flasks containing $10 \mathrm{ml}$ of growth medium, trypsinized $(0.05 \%)$ and split 1:5 every 3 days. Complete growth medium consisted of Dulbecco's Modifies Eagle Medium with F-12 (DMEM/F-12; GIBCO, Invitrogen, Paisley, UK) supplemented with horse serum (5\%), EGF (20 ng/ml), hydrocortisone (0.5 mg/ml), CT (100 ng/ml), insulin $(10 \mathrm{mg} / \mathrm{ml})$, and $5 \mathrm{ml} \mathrm{P/S}$. Cell cultures were maintained at $37{ }^{\circ} \mathrm{C}$ and $5 \% \mathrm{CO}_{2}$ in a humidified incubator.

\section{Exposure of MCF-10A cells to PFOS}

MCF-10A cells were trypsinized and resuspended in growth medium, plated in 96-well tissue-culture plates $\left(2 \times 10^{4}\right.$ cells/well), and allowed to attach for $24 \mathrm{~h}$ in a $5 \%$ $\mathrm{CO}_{2}$ humidified incubator at $37{ }^{\circ} \mathrm{C}$. After $24 \mathrm{~h}$, the cells were treated with different PFOS concentrations $(0-1 \mathrm{mM})$ dissolved in DMSO and assay medium (growth medium without horse serum and EGF). Controls were exposed to $0.1 \%$ DMSO only. The cells were incubated for 24,48 , and $72 \mathrm{~h}$. The experiments were repeated three times. 


\section{3-(4,5-dimethyl-2-yl)2,5-diphenyl-2H-tetrazolium bromide (MTT) assay}

MCF-10A cells were treated with different concentrations of PFOS (0-1 mM) for 24, 48, and $72 \mathrm{~h}$, with eight wells for each treatment and three independent experiments. Cell viability was measured by the MTT assay, which is based on the conversion of the tetrazolium salt to the colored product formazan. Only viable cells are able to reduce MTT. In brief, $0.5 \mathrm{mg}$ MTT was added to each well of the 96-well plates (containing $100 \mu \mathrm{l}$ medium and cells) $1 \mathrm{~h}$ before the end of incubation with PFOS. The supernatant was then separated, and $100 \mu \mathrm{l}$ dimethylsulfoxide (DMSO) was added to each well, followed by incubation and shaking for $10 \mathrm{~min}$. The formazan product generated during the incubation was solubilized in DMSO and measured at 490 and $630 \mathrm{~nm}$ using a Polarstar Optima microplate reader (Bmg Labtech, Offenburg, Germany).

To investigate the participation of estrogen receptors on the PFOS effects, the cells were preincubated $30 \mathrm{~min}$ with the ER receptor blocker ICI 182,780 $(100 \mathrm{nM})$, followed by incubation with PFOS $10 \mu \mathrm{M}$ for $72 \mathrm{~h}$, before the MTT assay was performed.

\section{Cell counting by DAPI staining}

MCF-10A cells were treated with different concentrations of PFOS (0-1 mM) for 24,48 , and $72 \mathrm{~h}$, with three replicates of each treatment. After the treatment, cells were fixed with 4\% paraformaldehyde for $30 \mathrm{~min}$ and permeabilized with $0.1 \%$ Triton X-100 in PBS for $5 \mathrm{~min}$ at room temperature. Cells were stained with DAPI $(0.25 \mathrm{mg} / \mathrm{ml})$ for $10 \mathrm{~min}$ at room temperature followed by two washes with PBS. Cells were viewed in an ImageXpress Micro XLS Widefield HighContent Analysis System (Molecular Devices, Sunnyvale CA, USA), and images analyzed with the SoftMax Pro Software after digital acquisition (Molecular Devices, Sunnyvale CA, USA).

\section{Analysis of cell-cycle phases and proteins involved in cell-cycle regulation}

Cells were processed for PI staining and flow cytometry as described previously (Pozarowski and Darzynkiewicz 2004). After 24, 48, and $72 \mathrm{~h}$, the supernatant was collected and monolayer exposed to $0.05 \%$ trypsin/EDTA. Cells were centrifugated at $92 \mathrm{~g}$ for $5 \mathrm{~min}$, and resuspended in $1 \mathrm{ml}$ PBS. After this, pelleted cells were fixed by dropwise adding $2 \mathrm{ml} \mathrm{70 \%} \mathrm{ice-cold} \mathrm{ethanol} \mathrm{while} \mathrm{vortexing} \mathrm{and} \mathrm{then} \mathrm{kept} \mathrm{on}$ ice for $1 \mathrm{~h}$ before storage at $4{ }^{\circ} \mathrm{C}$. The samples were stored for at least $48 \mathrm{~h}$ before analysis to allow leakage of fragmented DNA from apoptotic cells and their identification as a fraction with DNA content less than $\mathrm{G}_{0} / \mathrm{G}_{1}$, referred to as the sub- $\mathrm{G}_{0} / \mathrm{G}_{1}$ fraction. On the day of analysis, fixed cells were kept on ice and washed twice in PBS, and each sample incubated with $1 \mathrm{ml}$ PI $(50 \mathrm{mg} / \mathrm{ml})$ and RNAse A $(50 \mathrm{ng} /$ $\mathrm{ml}$ ) in PBS for $3 \mathrm{~h}$ at $4{ }^{\circ} \mathrm{C}$ in the dark. Forward and light scatter data were collected in a linear mode. Fluorescence data for 10,000 cells per sample were collected in the FL3 channel on a linear scale. Side- and forward-light scatter parameters were used to identify the cell events and doublets were excluded using gating. Samples were analyzed using a Cytoflex flow cytometer (Beckman Coulter Ltd., Brea, CA, USA). Cells in different cell-cycle phases were presented as a percentage of the total number of cells counted.

To evaluate the effects on proteins involved in cell-cycle regulation, cells were incubated with anti-Cyclin D, antiCDK4/6, and anti-p21/27/53 antibodies, and analyzed by flow cytometry. Cells were fixed with $0.4 \%$ paraformaldehyde and $1.5 \times 10^{6}$ cells were incubated overnight with different antibodies diluted in a block solution (BSA $1 \% /$ Triton X-100 2\%) in a saturated concentration, followed by incubation with goat anti-rabbit IgG 488 or goat anti-mouse IgG 555 as secondary antibody for $1 \mathrm{~h}$. Flow cytometry was performed using a Cytoflex flow cytometer (Beckman Coulter Ltd., Brea, CA, USA). Side and forward scatter of aggregates or lysed cells were determined using log scale SSC/ FSC plots with thresholds. Voltage settings for the SSC, FSC, and the fluorescent filters were kept constant for all experiments described. The results are expressed as mean fluorescence intensity compared with the controls (\% of controls) for 10,000 cells per sample.

\section{Immunocytochemistry}

MCF-10A cells were treated with $10 \mu \mathrm{M}$ PFOS $72 \mathrm{~h}$ and immunocytochemistry was performed as previously described (Pierozan et al. 2016). Briefly, cells plated on glass coverslips were fixed with $4 \%$ paraformaldehyde for 30 min and permeabilized with $0.1 \%$ Triton X-100 in PBS for $5 \mathrm{~min}$ at room temperature. After blocking with BSA $5 \%$, cells were incubated overnight with primary antibodies (1:1000). PBS washes and incubation with specific secondary antibodies conjugated with alexa-fluor 488 or 555 were performed for $1 \mathrm{~h}$. Negative control reactions were performed by omitting the primary antibody with no observed fluorescence. Nuclei were stained with DAPI $(0.25 \mathrm{mg} / \mathrm{ml})$. Cells were examined in an Olympus inverted microscope (Olympus, Tokyo, Japan), and images were collected with a $20 \times$ objective using constant intensity settings and exposure time for all samples. The intensity of the cell fluorescence was measured using the Image J Software (ImageJ2), and the fluorescence intensity was estimated as the difference between the measured fluorescence of the cells and the background. 


\section{Migration and invasion assay}

Transwell migration and invasion assays were conducted in 96-well plates with membrane inserts ( $8 \mu \mathrm{m}$ pore-size) (Corning, New York, NY, USA). Cells were treated with $10 \mu \mathrm{M}$ PFOS for $72 \mathrm{~h}$. After that, $5 \times 10^{5}$ cells were resuspended in $50 \mu \mathrm{l}$ of assay medium and seeded in the upper chamber of transwells with (invasion assay) or without (migration assay) Matrigel Matrix $(200 \mu \mathrm{g} / \mathrm{ml})$. The lower chamber contained $100 \mu \mathrm{l}$ growth medium. Cells were incubated for $24 \mathrm{~h}$ at $37{ }^{\circ} \mathrm{C}$ in a humidified atmosphere with $5 \% \mathrm{CO}_{2}$. At the end of incubation, non-invasive cells in the upper chamber were removed and invasive cells in the bottom were fixed with $4 \%$ formaldehyde and stained with DAPI and then were counted as described in the Sect. "Cell counting by DAPI staining" of "Materials and methods". Cells were viewed in an ImageXpress Micro XLS Widefield High-Content Analysis System (Molecular Devices, Sunnyvale, CA, USA), and images were analyzed with the SoftMax Pro Software after digital acquisition (Molecular Devices, Sunnyvale, CA, USA).

\section{Western blot analysis}

For the evaluation of ER protein levels, cells were exposed to $10 \mu \mathrm{M}$ PFOS or $10 \mathrm{nM} 17 \beta$-estradiol (E2-positive control) for $72 \mathrm{~h}$. Cells were then washed with ice-cold PBS and lysed with Laemmli lysis buffer. The protein concentration in cell lysates was determined using bicinchoninic acid protein assay (Smith et al. 1985). Equal amounts of protein $(30 \mu \mathrm{g})$ were separated by sodium dodecyl sulfate-polyacrylamide gel electrophoresis (SDS-PAGE) on 10\% gel and transferred (Mini Trans-Blot Electrophoretic Transfer Cell-Bio-Rad, Hercules, CA, USA) to polyvinylidene difluoride membranes for $1 \mathrm{~h}$ at $100 \mathrm{~V}$ in transfer buffer (25 mM Triz, $192 \mathrm{M}$ glycine, 20\% methanol and $0.1 \% \mathrm{SDS}$ ). The blot was then washed for $20 \mathrm{~min}$ in Tris-buffered saline (TBS; $500 \mathrm{mM} \mathrm{NaCl,} 20 \mathrm{mM}$ Trizma, $\mathrm{pH} 7.5)$, followed by $2 \mathrm{~h}$ incubation in blocking solution (TBS plus 5\% defatted dry milk). After the incubation was finished, the blot was washed twice for 5 min with blocking solution plus $0.05 \%$ Tween-20 (T-TBS) and incubated overnight at $4{ }^{\circ} \mathrm{C}$ in blocking solution containing monoclonal antibodies diluted 1:1000. The blot was then washed twice for 5 min with T-TBS and incubated for $2 \mathrm{~h}$ in a solution containing peroxidase-conjugated rabbit anti-mouse IgG-diluted 1:2000 or peroxidase-conjugated anti-rabbit IgG-diluted 1:2000. The blot was washed twice with T-TBS for $5 \mathrm{~min}$ and twice with TBS for $5 \mathrm{~min}$. The blot was developed with the chemiluminescence ECL kit (Little Chalfont, UK).

\section{Statistical analysis}

The results were presented as mean \pm standard deviation (SD) for each experimental group of at least three individual samples. Differences between the control were analyzed by one-way analysis of variance (ANOVA) followed by Tukey-Kramer multiple tests using Graphpad Prism 7 software.

\section{Results}

\section{PFOS-induced cell death and proliferation are dependent on the time and concentration}

To determine whether PFOS exposure can induce cell death or proliferation, cells were incubated with 0-1 mM PFOS for 24,48 , and $72 \mathrm{~h}$, and cell viability determined by the MTT assay. We found significantly decreased cell viability in PFOS concentrations equal to $250 \mu \mathrm{M}$ or higher at all time points (Fig. 1a, c). In contrast, exposure to $10 \mu \mathrm{M}$ PFOS for $48 \mathrm{~h}$ (Fig. 1b) and 1 and $10 \mu \mathrm{M}$ PFOS for $72 \mathrm{~h}$ (Fig. 1c) increased MTT production, suggesting an increase in cell proliferation. To confirm this observation, the number of cells was determined using DAPI staining and fluorescence microscopy. The results showed that PFOS caused an increase in the number of cells at $10 \mu \mathrm{M} 24 \mathrm{~h}$ and $48 \mathrm{~h}$ exposure (Fig. 1d, e) as well as 1 and $10 \mu \mathrm{M}$ at $72 \mathrm{~h}$ (Fig. 1f).

\section{PFOS affects the cell cycle in MCF-10A cells}

To determine the effects of PFOS exposure on cell-cycle distribution, cells were stained with PI and analyzed by flow cytometry. Table 1 shows the mean percentage of gated cells for each DNA content fraction $\left(\mathrm{G}_{0} / \mathrm{G}_{1}, \mathrm{~S}, \mathrm{G}_{2} / \mathrm{M}\right)$ following 24, 48, and $72 \mathrm{~h}$ exposure to $10 \mu \mathrm{M}$ PFOS. PFOS exposure reduced the percentage of cells in $G_{0} / G_{1}$ phase and increased the percentage of cells in $\mathrm{S}$ phase at all time points.

\section{PFOS alters the levels of proteins involved in cell-cycle regulation}

To investigate mechanisms involved in PFOS-induced cell proliferation in MCF-10A cells, the levels of the cyclindependent kinases (CDKs) CDK4, CDK6, Cyclin D1, and their respective inhibitors (p27, p21, and p53) were analyzed by immunocytochemistry and flow cytometry and compared with control cells. The fluorescence microscopy images revealed a reduced p27, p21, and p53-fluorescence (Fig. 2a, b, g, h, and i), and an increased CDK4 fluorescence (Fig. 2d, f) in cells treated with PFOS, with no alteration in CDK6 and Cyclin D1-staining (Fig. 2a, c, d and e). The flow cytometry results confirmed the immunocytochemistry findings and 
Fig. 1 Effects of PFOS on the viability of MCF-10A cells. The cells were exposed to $0-1 \mathrm{mM}$ PFOS for 24, 48, and $72 \mathrm{~h}$. The controls were incubated with $0.1 \%$ dimethylsulfoxide (DMSO). The viability was determined by MTT assay (a, $\mathbf{b}$, and $\mathbf{c}$ ) and DAPI staining $(\mathbf{d}, \mathbf{e}$, and $\mathbf{f})$. Values represent mean \pm SD from three independent experiments. Statistically significant differences from control are indicated as follows $* * * p<0.001$; $* * p<0.01$ and $* p<0.05$ (Oneway ANOVA followed by the Tukey-Kramer test)
A



B

$48 \mathrm{H}$
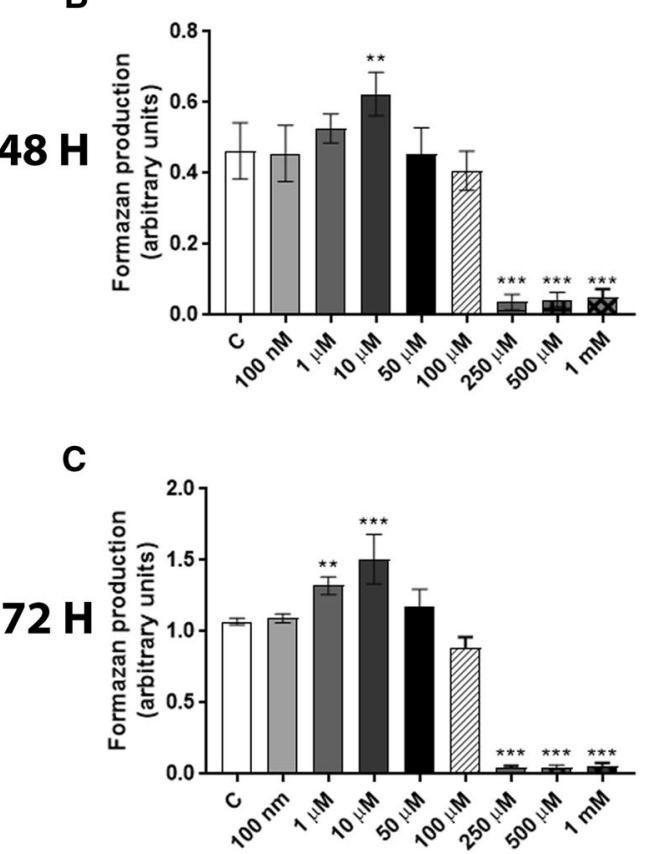

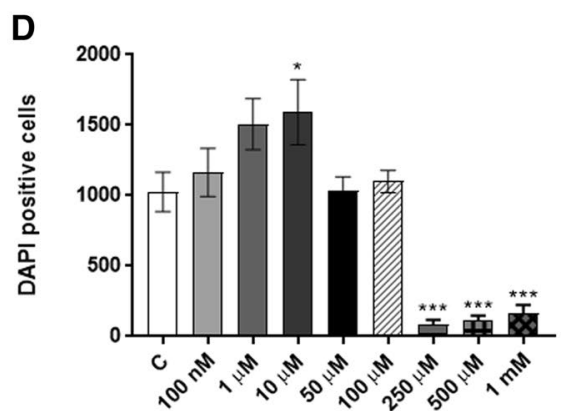

E

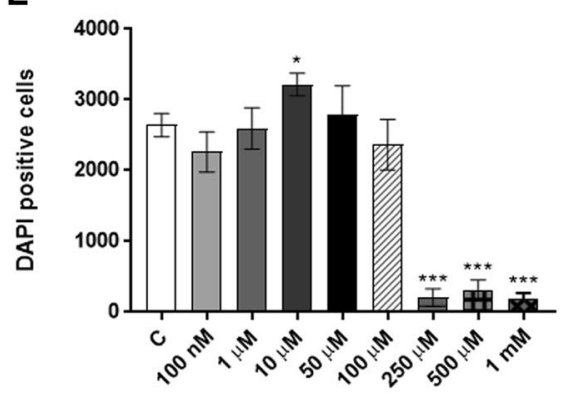

$\mathbf{F}$

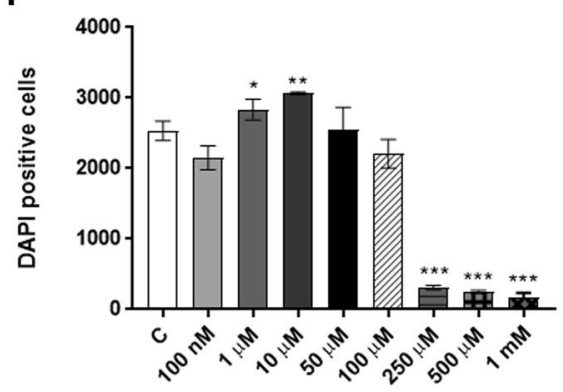

Table 1 Effects of PFOS $(10 \mu \mathrm{M})$ on MCF-10A cell cycle

\begin{tabular}{|c|c|c|c|c|c|c|c|c|c|}
\hline & \multicolumn{3}{|l|}{$24 \mathrm{~h}$} & \multicolumn{3}{|l|}{$48 \mathrm{~h}$} & \multicolumn{3}{|l|}{$72 \mathrm{~h}$} \\
\hline & G0/G1 & $S$ & $\mathrm{G} 2 / \mathrm{M}$ & G0/G1 & $S$ & $\mathrm{G} 2 / \mathrm{M}$ & G0/G1 & $S$ & $\mathrm{G} 2 / \mathrm{M}$ \\
\hline Control & $68.3 \pm 15$ & $17.0 \pm 10$ & $10 \pm 6.17$ & $51.3 \pm 6.7$ & $34.0 \pm 6.8$ & $14.7 \pm 0.3$ & $56.0 \pm 5.4$ & $33.1 \pm 7.9$ & $10.9 \pm 2.6$ \\
\hline PFOS & $54.4 \pm 7.8 * * *$ & $36.2 \pm 3.6^{* *}$ & $13.4 \pm 2.5$ & $36.2 \pm 1.3^{* *}$ & $57.2 \pm 2.3^{* * *}$ & $6.6 \pm 1.2 * * *$ & $32.9 \pm 1.9 * * *$ & $57.7 \pm 7.5^{* *}$ & $9.4 \pm 6.0$ \\
\hline
\end{tabular}

Results as percentage of total events (10 000 events)

Statistically significant differences from control are indicated as follows $* * * p<0.001$ and $* * p<0.01$ (Student's $t$ test)

showed a decrease in the mean fluorescence intensity in p27, p21, and p53-staining (Fig. 2j, $\mathrm{n}$ and o), and an increase in the mean fluorescence intensity in CKD4-staining (Fig. 2m) in PFOS-treated cells compared to the controls.

\section{PFOS promotes migration and invasion of MCF-10A cells}

To further investigate the effect of PFOS on cell aggression, we analyzed the effect of the compound on migration and invasion of MCF-10A cells using transwell migration and Matrigel invasion assays. As demonstrated in Fig. 4, the migration (Fig. 3a) and invasion capacity (Fig. 3b) of the MCF-10A cells were enhanced after treatment with PFOS, indicating that PFOS induces invasive abilities compared with the untreated control cells.

\section{Effect of PFOS on ER $\alpha$ and ERß protein levels and ER activation in MCF-10A cells}

Since it has been shown that PFOS can interact directly or indirectly with estrogenic pathways (Kortenkamp 2006; 

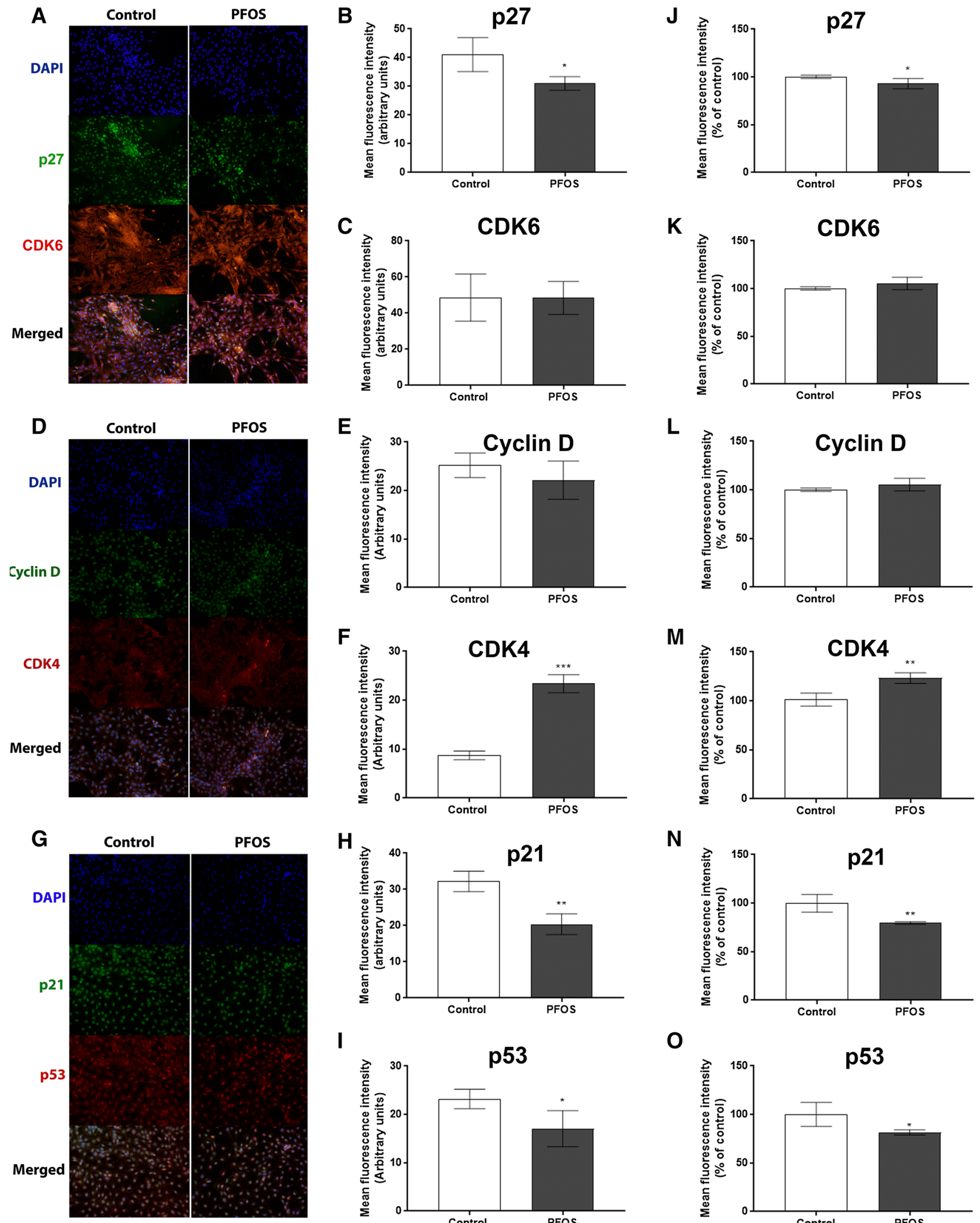

N
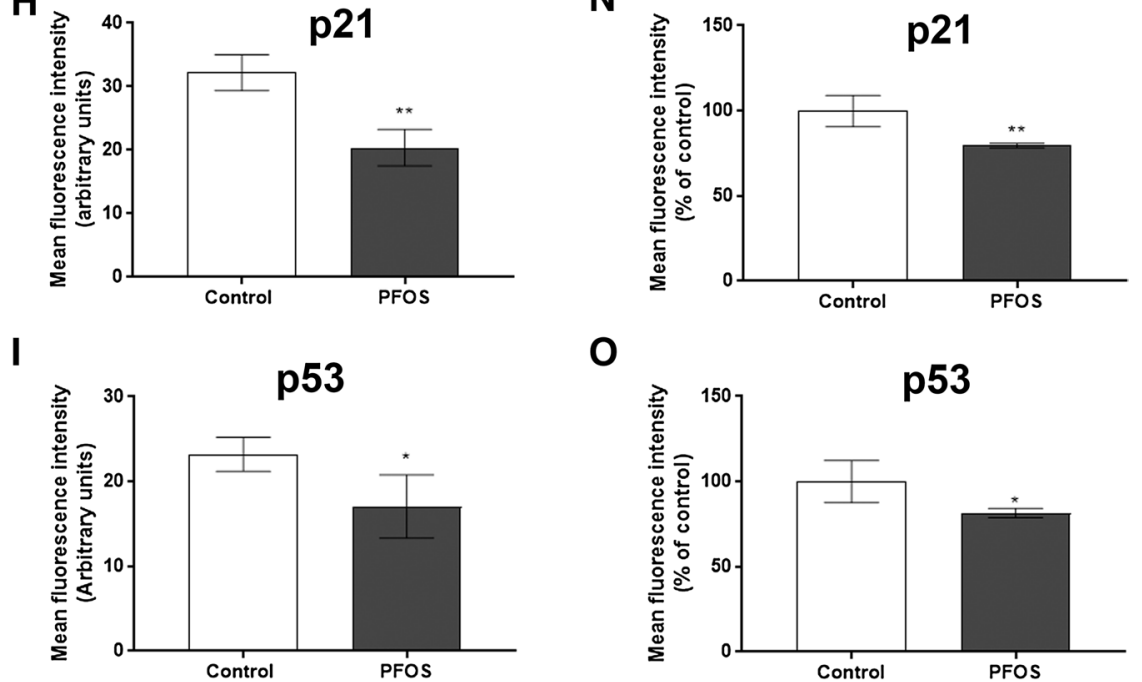

O




4Fig. 2 Effects of PFOS on the levels of proteins involved in cellcycle regulation. The cells were exposed to $10 \mu \mathrm{M}$ PFOS for $72 \mathrm{~h}$ before immunocytochemistry and flow cytometry was performed. Representative images of PFOS-treated cells immunostained with p27 and CDK6 (a), Cyclin D1 and CDK4 (b), and p21 and p53 (c). Mean fluorescence intensity was analyzed from immunocytochemistry $(\mathbf{b}-\mathbf{i})$ and flow cytometry $(\mathbf{j}-\mathbf{o})$ as described in Materials and methods section. Values represent mean \pm SD from three independent experiments. Statistically significant differences from control are indicated as follows: ${ }^{* * *} p<0.001$; $* p<0.01$ and $* p<0.05$ (Student's $t$ test)

Sonthithai et al. 2016), and MCF-10A cells can be transformed into a malignant phenotype by estrogen compounds (Hemachandra et al. 2012), we investigate the effects of PFOS on ER protein levels and the role of ER activation. In MCF-10A cells, 17 $\beta$-estradiol (E2), used as positive control, increased ER $\alpha$ (Fig. 4a) and ER $\beta$ (Fig. 4b) levels after $72 \mathrm{~h}$ of exposure, while PFOS had no effect on ER $\alpha$ and ER $\beta$ levels. Moreover, treatment of MCF-10A cells with the ER receptor blocker, ICI 182,780 prevented only partially the stimulatory effects of PFOS on cell proliferation (Fig. 4c).

\section{Discussion}

Breast cancer is one of the most common malignancies affecting women in Western countries (Gullick et al. 1998). Despite extensive research efforts to understand and eradicate breast cancer, the cellular processes that can lead to the onset of mammary carcinogenesis have yet to be elucidated in detail. Among many breast cancer risk factors, estrogens and non-estrogenic endocrine disruptors are considered to play critical roles in human breast carcinogenesis (Brody et al. 2007). Several common persistent organic pollutants are endocrine disrupters and suggested to play an important role in cancer etiology. These persistent and lipophilic compounds have been associated with effects relevant for development of breast cancer such as estrogenic, tumor promoting, and immunosuppressive activities (Bonefeld-Jorgensen et al. 2011).

There is growing evidence that PFOS may disrupt the endocrine system (Johansson et al. 2008; Wang et al. 2011). It has been shown to exhibit weak antagonistic ER transactivation, induce estradiol (E2) levels, and reduce testosterone levels in a cell line study (Kang et al. 2016). Moreover, a human study showed a significant inverse association between PFOS and estradiol in perimenopausal and menopausal women (Knox et al. 2011). However, the molecular mechanisms downstream these effects are still unclear.

In our present work, we have demonstrated that PFOS can induce cell proliferation in the MCF-10A breast cell line, through cell-cycle progression by altering the levels of proteins involved in cell-cycle regulation. PFOS induce cell proliferation, by down-regulation of $\mathrm{p} 53$, $\mathrm{p} 21$, and $\mathrm{p} 27$ and up-regulation of CDK4 levels, subsequently resulting in MCF-10A transformation. Importantly, PFOS also stimulated cell migration and invasion, illustrating its capability of inducing neoplastic transformation of human normal breast epithelial cells.

Unrestricted proliferation is a hallmark of cancer cells and is frequently associated with impaired cell-cycle regulation, and dysregulation of components involved in cellcycle control occurs frequently in breast cancer (Cancer Genome Atlas 2012). A crucial abnormality that occurs during tumor development is the loss of control at the G1-to-S transition, which is a period during which cells decide to enter in the cell cycle on mitogenic stimuli. The progression through the G1-S phase requires phosphorylation of the retinoblastoma protein by CDK4 or CDK6 (Lundberg and Weinberg 1998). These enzymes, along with their corresponding cyclins D allow the cell to enter or not in the S phase (Berthet and Kaldis 2007). The observed PFOS induction of CDK4 levels could explain the increase in MCF-10A cell proliferation found in our studies. In line with this, deregulation of CDKs are common hallmarks

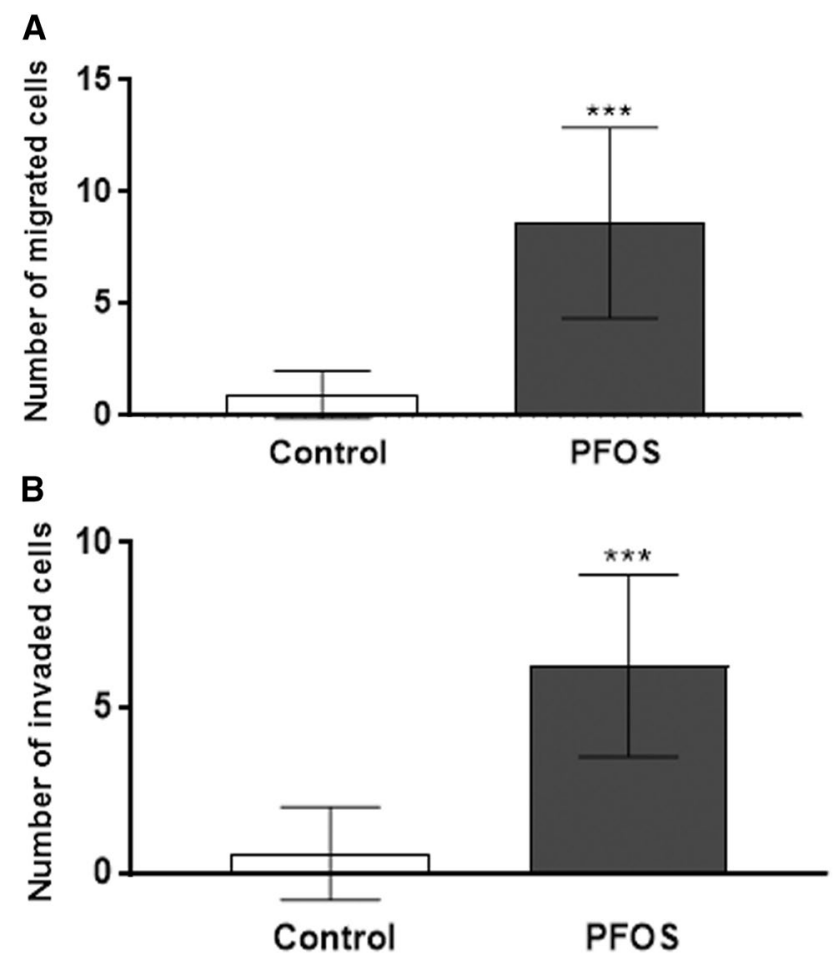

Fig. 3 Effects of PFOS on MCF-10A cell migration and invasion capacity. Effects of PFOS on MCF-10A cell migration (a) and cell invasion (b) by a transwell assay. Migrated or invaded cells in the bottom were fixed with $4 \%$ formaldehyde and stained with DAPI and counted as described in the Materials and methods section. Values represent mean $\pm \mathrm{SD}$. Statistically significant differences from control are indicated as follows $* * * p<0.001$ (Student's $t$ test) 
Fig. 4 Involvement of the ER in the effects triggered by PFOS. Effect of PFOS and 17 $\beta$-estradiol (E2-positive control) on ER $\alpha$ (a) and $\operatorname{ER} \beta$ (b) protein levels in MCF-10A breast cells. The cells were exposed to $10 \mu \mathrm{M}$ PFOS or $10 \mathrm{nM}$ E2 for $72 \mathrm{~h}$. $\beta$-tubulin was used as a loading control. Representative blots of three experiments are shown. The results of densitometry analysis are expressed as ER protein band density normalized to the density of $\beta$-tubulin bands. To determine the role of ER activation, cells were incubated with $100 \mathrm{nM}$ ICI 182,780 followed by $10 \mu \mathrm{M}$ PFOS, and the viability was determined by MTT assay (c). Data are reported as mean \pm SD of three independent experiments. Statistically significant differences from control are indicated as follows $* * p<0.01$ and $* p<0.05$ (Oneway ANOVA followed by the Tukey-Kramer test)

in cell-cycle alterations found in tumors (Dickson 2014), and CDK4/6 has a pivotal role in the G1-to-S-phase cellcycle transition in cancer (O'Leary et al. 2016). Moreover, CDK4 is found to be highly expressed in aggressive tumors and its expression correlate with poor overall and relapsefree survival outcomes as well as poor prognostic features of breast cancer patients, suggesting a central role for this protein in cancer development and progression (Massague 2004).

Concomitant with an increase in CDK4 levels, we found a decrease in p27, p21 and p53 levels. The protein inhibitors p27 and p21 negatively regulate the G1-to-S phase progression by binding to and inhibiting Cyclin E-CDK2 or Cyclin D-CDK4 (Sherr and Roberts 1999). Decreased expression of these cell-cycle inhibitors is associated with the promotion of tumor formation and a poor prognosis in many types of cancers (Burton et al. 2000). Low levels or loss of p27 and p21 expression is a significant predictor of reduced survival, tumor progression, and prognosis (Abbas and Dutta 2009; Catzavelos et al. 1997). Moreover, the p27 levels usually decrease during tumor development and progression (Vidal and Koff 2000), and there is considerable evidence that p27 inactivation is fundamental for development of malignancies (Loda et al. 1997). p21 expression is tightly controlled by the well-known tumor suppressor p53, involved in p53-dependent cell-cycle arrest, DNA repair, and apoptosis in response to various cellular stressors (Cmielova and Rezacova 2011). However, p53 is the most frequently mutated gene in human cancers and $15-60 \%$ of breast cancers contain a p53 mutation. In addition, loss of p53 by degradation has been reported in several common human cancers and might be associated with poor prognosis and death in breast cancer patients (Gasco et al. 2002).

Invasion and metastasis of aggressive breast cancer cells are the final and fatal step during cancer progression (McAllister et al. 2011). To form metastasis, cancer cells must escape the primary tumor site, migrate into surrounding tissues, and colonize a distant organ. The first barrier faced by invasive cancer cells is the basement membrane, a dense and rigid matrix. Using a transwell and matrigel assay, we
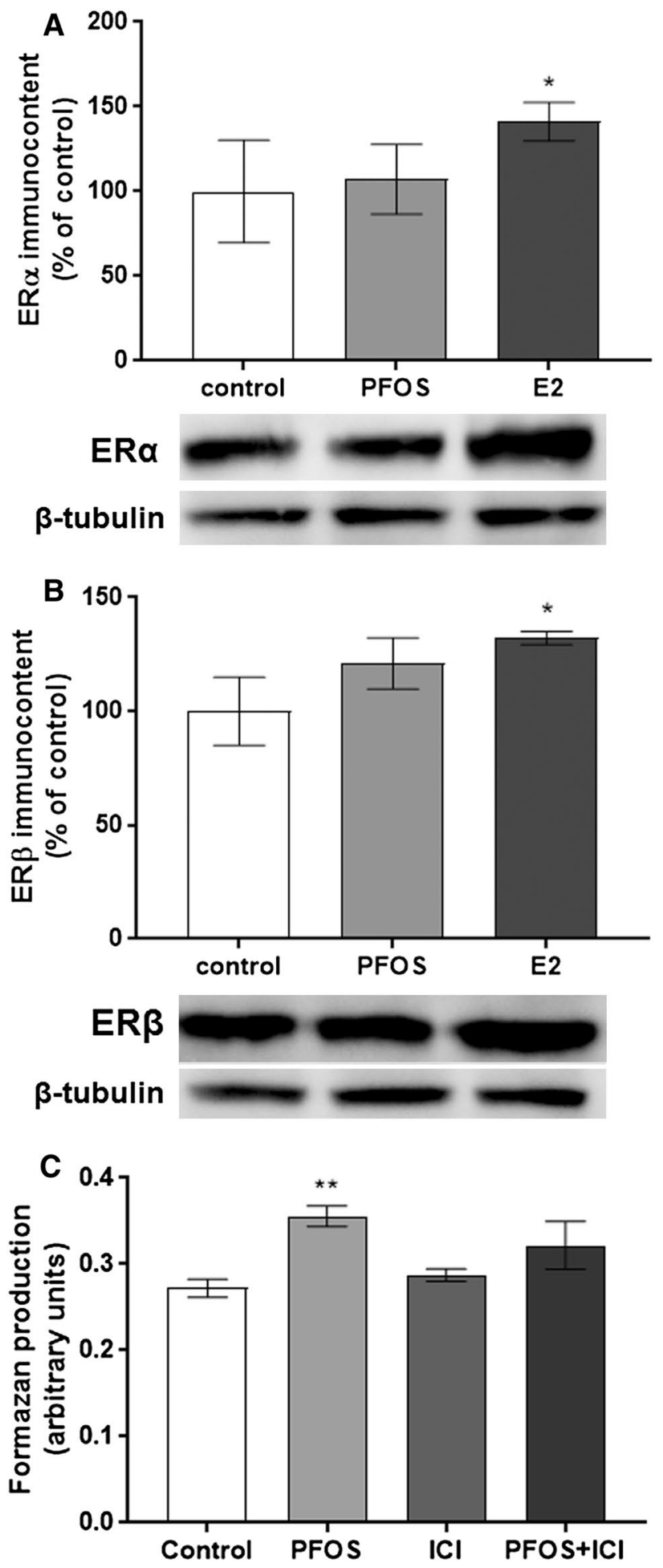

showed that PFOS enhanced the migration and invasion capacity of MCF-10A cells. This effect could be related with the decreased levels of p27, p21, and p53, since it is well known that decreased concentrations of these inhibitors are implicated in human tumorigenesis or oncogenic 
Fig. 5 Schematic model of how PFOS may promote cell-cycle progression, and stimulate cell proliferation and transformation in MCF-10A cells. PFOS acts through ER and possibly VEGR/HER2, up-regulating CDK4 and down-regulating p27, p21, and p53, to drive cells into the cell cycle from $\mathrm{G}_{1}$ to $\mathrm{S}$, promoting cell-cycle progression

\section{PFOS}



CELL TRANSFORMATION progression in many human malignancies (Alkarain and Slingerland 2004).

Estrogen-a primary sex hormone responsible for mammary gland development-exerts many of its effects through the two nuclear receptors $\mathrm{ER} \alpha$ and $\mathrm{ER} \beta$ (Lee et al. 2012). In the mammary gland, ER $\alpha$ promotes proliferation, whereas ER $\beta$ inhibits ER $\alpha$-mediated proliferation (Chang et al. 2006). Most of the human breast cancers are initially estrogen-dependent wherein ER $\alpha$ expression contributes significantly to the etiology of the disease (Black et al. 1983). Estrogen-activated ER $\alpha$ regulates the expression of several key cell-cycle regulatory genes, such as c-myc, c-fos, and cyclin D1 (Prall et al. 1997; van der Burg et al. 1989). On the other hand, studies have reported that ER $\beta$ is frequently lost during carcinogenesis, suggesting a role for ER $\beta$ as a tumor suppressor (Park et al. 2003; Skliris et al. 2003). In line with this, estrogen and estrogenic compounds can cause malignant transformation of normal breast epithelial cells through activation-expression of these two ER (Wang et al. 2013). We show that PFOS had no effect on ER $\alpha$ and ER $\beta$ protein expression in MCF-10A cells. However, the ER blocker ICI 182,780 partially prevented the cell proliferation caused by the compound, suggesting that the stimulatory effects on MCF-10A proliferation - at least in part-is by activation of ER receptors. Nonetheless, other mechanisms are involved in its actions. Several molecular mechanisms have been identified which may be implicated in the loss of ER response during tumor progression. Increased expression of growth factor receptor pathways, especially EGFR/HER2, and concomitant loss of the p53, has been associated with 
endocrine therapy resistance (Osborne and Schiff 2011). In addition, reduced expression or activity of p21 and p27 is also associated with ER-negative breast cancer (Chu et al. 2008; Perez-Tenorio et al. 2006). Other studies have shown that pathways such as receptors for insulin/IGF1, FGF, and VEGF, as well as cellular Src, AKT, and stress-related kinases have been implicated in the transformation of ERpositive to ER-negative breast cancers (Chakraborty et al. 2010; Kern et al. 1994; Morgan et al. 2009). An overview of the proposed mechanism of PFOS toxicity is depicted in Fig. 5. However, the exact mechanisms by which PFOS are affecting the MCF-10A proliferation need to be elucidated.

In summary, PFOS significantly stimulates MCF-10A proliferation in a dose-dependent manner, which alters the levels of important proteins involved in cell-cycle regulation, subsequently resulting in cell transformation. Interestingly, MCF-10A cells also acquire the capability of migration and invasion after PFOS treatment. These effects are partially caused by activation of ER. The results suggest that PFOS is capable of transforming the human normal breast epithelial cell line MCF-10A to a malignant profile. This is the first study demonstrating PFOS-induced transformation of MCF-10A, which might be mediated by its up-regulation of CDK4 and down-regulation of p53, p21, and p27. Consequently, PFOS might play a role in breast neoplasia and breast cancer development. These results implicate PFOS exposure as a potential risk factor for breast cancer. Further experimental and epidemiological studies are warranted to determine detailed mechanisms and elucidate the role of PFOS exposure in breast cancer etiology.

Acknowledgements The BioVis platform at Uppsala University is gratefully acknowledge for providing the flow cytometry equipment and excellent support.

Open Access This article is distributed under the terms of the Creative Commons Attribution 4.0 International License (http://creativecommons.org/licenses/by/4.0/), which permits unrestricted use, distribution, and reproduction in any medium, provided you give appropriate credit to the original author(s) and the source, provide a link to the Creative Commons license, and indicate if changes were made.

\section{References}

Abbas T, Dutta A (2009) p21 in cancer: intricate networks and multiple activities. Nat Rev Cancer 9(6):400-414. doi:10.1038/nrc2657

Alkarain A, Slingerland J (2004) Deregulation of p27 by oncogenic signaling and its prognostic significance in breast cancer. Breast Cancer Res 6(1):13-21. doi:10.1186/bcr722

Benninghoff AD, Bisson WH, Koch DC, Ehresman DJ, Kolluri SK, Williams DE (2011) Estrogen-like activity of perfluoroalkyl acids in vivo and interaction with human and rainbow trout estrogen receptors in vitro. Toxicol Sci 120(1):42-58. doi:10.1093/toxsci/ kfq379
Berthet C, Kaldis P (2007) Cell-specific responses to loss of cyclindependent kinases. Oncogene 26(31):4469-4477. doi:10.1038/ sj.onc. 1210243

Black R, Prescott R, Bers K, Hawkins A, Stewart H, Forrest P (1983) Tumour cellularity, oestrogen receptors and prognosis in breast cancer. Clin Oncol 9(4):311-318

Bonefeld-Jorgensen EC, Long M, Bossi R et al (2011) Perfluorinated compounds are related to breast cancer risk in Greenlandic Inuit: a case control study. Environ Health 10:88. doi:10.1186/1476-069X-10-88

Boulanger B, Vargo JD, Schnoor JL, Hornbuckle KC (2005) Evaluation of perfluorooctane surfactants in a wastewater treatment system and in a commercial surface protection product. Environ Sci Technol 39(15):5524-5530

Brody JG, Moysich KB, Humblet O, Attfield KR, Beehler GP, Rudel RA (2007) Environmental pollutants and breast cancer: epidemiologic studies. Cancer 109(12 Suppl):2667-2711. doi:10.1002/ cncr.22655

Burton PB, Anderson CJ, Corbishly CM (2000) Caspase 3 and p27 as predictors of invasive bladder cancer. N Engl J Med 343(19):1418-1420. doi:10.1056/NEJM200011093431915

Cancer Genome Atlas N (2012) Comprehensive molecular portraits of human breast tumours. Nature 490(7418):61-70. doi:10.1038/ nature 11412

Catzavelos C, Bhattacharya N, Ung YC et al (1997) Decreased levels of the cell-cycle inhibitor p27Kip1 protein: prognostic implications in primary breast cancer. Nat Med 3(2):227-230

Chakraborty AK, Welsh A, Digiovanna MP (2010) Co-targeting the insulin-like growth factor I receptor enhances growth-inhibitory and pro-apoptotic effects of anti-estrogens in human breast cancer cell lines. Breast Cancer Res Treat 120(2):327-335. doi:10.1007/ s10549-009-0382-5

Chang EC, Frasor J, Komm B, Katzenellenbogen BS (2006) Impact of estrogen receptor beta on gene networks regulated by estrogen receptor alpha in breast cancer cells. Endocrinology 147(10):4831-4842. doi:10.1210/en.2006-0563

Chang SC, Thibodeaux JR, Eastvold ML et al (2008) Thyroid hormone status and pituitary function in adult rats given oral doses of perfluorooctanesulfonate (PFOS). Toxicology 243(3):330-339. doi:10.1016/j.tox.2007.10.014

Chu IM, Hengst L, Slingerland JM (2008) The Cdk inhibitor p27 in human cancer: prognostic potential and relevance to anticancer therapy. Nat Rev Cancer 8(4):253-267. doi:10.1038/nrc2347

Cmielova J, Rezacova M (2011) p21Cip1/Waf1 protein and its function based on a subcellular localization [corrected]. J Cell Biochem 112(12):3502-3506. doi:10.1002/jcb.23296

Dickson MA (2014) Molecular pathways: CDK4 inhibitors for cancer therapy. Clin Cancer Res 20(13):3379-3383. doi:10.1158/10780432.CCR-13-1551

Du G, Hu J, Huang H et al (2013) Perfluorooctane sulfonate (PFOS) affects hormone receptor activity, steroidogenesis, and expression of endocrine-related genes in vitro and in vivo. Environ Toxicol Chem 32(2):353-360. doi:10.1002/etc.2034

Gallo V, Leonardi G, Genser B et al (2012) Serum perfluorooctanoate (PFOA) and perfluorooctane sulfonate (PFOS) concentrations and liver function biomarkers in a population with elevated PFOA exposure. Environ Health Perspect 120(5):655-660. doi:10.1289/ ehp. 1104436

Gasco M, Shami S, Crook T (2002) The p53 pathway in breast cancer. Breast Cancer Res 4(2):70-76

Giesy JP, Kannan K, Jones PD (2001) Global biomonitoring of perfluorinated organics. Sci World J 1:627-629. doi:10.1100/ tsw. 2001.342

Gullick JW, Bianco C, Normanno N et al (1998) Growth factors and their receptors: a novel approach to the endocrinology of human breast cancer. Women Cancer 1:29-59 
Hemachandra LP, Madhubhani P, Chandrasena R et al (2012) Hops (Humulus lupulus) inhibits oxidative estrogen metabolism and estrogen-induced malignant transformation in human mammary epithelial cells (MCF-10A). Cancer Prev Res (Phila) 5(1):73-81. doi:10.1158/1940-6207.CAPR-11-0348

Ishibashi H, Ishida H, Matsuoka M, Tominaga N, Arizono K (2007) Estrogenic effects of fluorotelomer alcohols for human estrogen receptor isoforms alpha and beta in vitro. Biol Pharm Bull 30(7):1358-1359

Jensen AA, Leffers H (2008) Emerging endocrine disrupters: perfluoroalkylated substances. Int J Androl 31(2):161-169. doi:10.1111/j.1365-2605.2008.00870.x

Johansson N, Fredriksson A, Eriksson P (2008) Neonatal exposure to perfluorooctane sulfonate (PFOS) and perfluorooctanoic acid (PFOA) causes neurobehavioural defects in adult mice. Neurotoxicology 29(1):160-169. doi:10.1016/j.neuro.2007.10.008

Kang JS, Choi JS, Park JW (2016) Transcriptional changes in steroidogenesis by perfluoroalkyl acids (PFOA and PFOS) regulate the synthesis of sex hormones in H295R cells. Chemosphere 155:436-443. doi:10.1016/j.chemosphere.2016.04.070

Karrman A, Ericson I, van Bavel B et al (2007) Exposure of perfluorinated chemicals through lactation: levels of matched human milk and serum and a temporal trend, 1996-2004, in Sweden. Environ Health Perspect 115(2):226-230. doi:10.1289/ehp.9491

Kern FG, McLeskey SW, Zhang L et al (1994) Transfected MCF-7 cells as a model for breast-cancer progression. Breast Cancer Res Treat 31(2-3):153-165

Kjeldsen LS, Bonefeld-Jorgensen EC (2013) Perfluorinated compounds affect the function of sex hormone receptors. Environ Sci Pollut Res Int 20(11):8031-8044. doi:10.1007/s11356-013-1753-3

Knox SS, Jackson T, Javins B, Frisbee SJ, Shankar A, Ducatman AM (2011) Implications of early menopause in women exposed to perfluorocarbons. J Clin Endocrinol Metab 96(6):1747-1753. doi:10.1210/jc.2010-2401

Kortenkamp A (2006) Breast cancer, oestrogens and environmental pollutants: a re-evaluation from a mixture perspective. Int $\mathbf{J}$ Androl 29(1):193-198. doi:10.1111/j.1365-2605.2005.00613.x

Lee HR, Kim TH, Choi KC (2012) Functions and physiological roles of two types of estrogen receptors, ERalpha and ERbeta, identified by estrogen receptor knockout mouse. Lab Anim Res 28(2):71-76. doi:10.5625/lar.2012.28.2.71

Lindstrom AB, Strynar MJ, Libelo EL (2011) Polyfluorinated compounds: past, present, and future. Environ Sci Technol 45(19):7954-7961. doi:10.1021/es2011622

Loda M, Cukor B, Tam SW et al (1997) Increased proteasome-dependent degradation of the cyclin-dependent kinase inhibitor p27 in aggressive colorectal carcinomas. Nat Med 3(2):231-234

Lundberg AS, Weinberg RA (1998) Functional inactivation of the retinoblastoma protein requires sequential modification by at least two distinct cyclin-cdk complexes. Mol Cell Biol 18(2):753-761

Maras M, Vanparys C, Muylle F et al (2006) Estrogen-like properties of fluorotelomer alcohols as revealed by mcf-7 breast cancer cell proliferation. Environ Health Perspect 114(1):100-105

Massague J (2004) G1 cell-cycle control and cancer. Nature 432(7015):298-306. doi:10.1038/nature03094

McAllister SD, Murase R, Christian RT et al (2011) Pathways mediating the effects of cannabidiol on the reduction of breast cancer cell proliferation, invasion, and metastasis. Breast Cancer Res Treat 129(1):37-47. doi:10.1007/s10549-010-1177-4

Morgan L, Gee J, Pumford S et al (2009) Elevated Src kinase activity attenuates Tamoxifen response in vitro and is associated with poor prognosis clinically. Cancer Biol Ther 8(16):1550-1558

O'Leary B, Finn RS, Turner NC (2016) Treating cancer with selective CDK4/6 inhibitors. Nat Rev Clin Oncol 13(7):417-430. doi:10.1038/nrclinonc.2016.26
Olsen GW, Burris JM, Mandel JH, Zobel LR (1999) Serum perfluorooctane sulfonate and hepatic and lipid clinical chemistry tests in fluorochemical production employees. J Occup Environ Med 41(9):799-806

Olsen GW, Burris JM, Ehresman DJ et al (2007) Half-life of serum elimination of perfluorooctanesulfonate, perfluorohexanesulfonate, and perfluorooctanoate in retired fluorochemical production workers. Environ Health Perspect 115(9):1298-1305. doi:10.1289/ehp.10009

Osborne CK, Schiff R (2011) Mechanisms of endocrine resistance in breast cancer. Annu Rev Med 62:233-247. doi:10.1146/ annurev-med-070909-182917

Park BW, Kim KS, Heo MK et al (2003) Expression of estrogen receptor-beta in normal mammary and tumor tissues: is it protective in breast carcinogenesis? Breast Cancer Res Treat 80(1):79-85. doi: 10.1023/A:1024406223619

Parsons JR, Saez M, Dolfing J, de Voogt P (2008) Biodegradation of perfluorinated compounds. Rev Environ Contam Toxicol 196:53-71

Perez-Tenorio G, Berglund F, Esguerra Merca A et al (2006) Cytoplasmic p21WAF1/CIP1 correlates with Akt activation and poor response to tamoxifen in breast cancer. Int $\mathrm{J}$ Oncol 28(5):1031-1042

Pierozan P, Biasibetti H, Schmitz F et al (2016) Quinolinic acid neurotoxicity: Differential roles of astrocytes and microglia via FGF-2-mediated signaling in redox-linked cytoskeletal changes. Biochim Biophys Acta 1863(12):3001-3014. doi:10.1016/j. bbamcr.2016.09.014

Pozarowski P, Darzynkiewicz Z (2004) Analysis of cell cycle by flow cytometry. Methods Mol Biol 281:301-311. doi:10.1385/1-59259-811-0:301

Prall OW, Sarcevic B, Musgrove EA, Watts CK, Sutherland RL (1997) Estrogen-induced activation of Cdk4 and Cdk2 during G1-S phase progression is accompanied by increased cyclin D1 expression and decreased cyclin-dependent kinase inhibitor association with cyclin E-Cdk2. J Biol Chem 272(16):10882-10894

Saikat S, Kreis I, Davies B, Bridgman S, Kamanyire R (2013) The impact of PFOS on health in the general population: a review. Environ Sci Process Impacts 15(2):329-335. doi:10.1039/ c2em30698k

Sherr CJ, Roberts JM (1999) CDK inhibitors: positive and negative regulators of G1-phase progression. Genes Dev 13(12):1501-1512

Skliris GP, Munot K, Bell SM et al (2003) Reduced expression of oestrogen receptor beta in invasive breast cancer and its re-expression using DNA methyl transferase inhibitors in a cell line model. J Pathol 201(2):213-220. doi:10.1002/path.1436

Skutlarek D, Exner M, Farber H (2006) Perfluorinated surfactants in surface and drinking waters. Environ Sci Pollut Res Int 13(5):299-307

Smith PK, Krohn RI, Hermanson GT et al (1985) Measurement of protein using bicinchoninic acid. Anal Biochem 150(1):76-85

Sonthithai P, Suriyo T, Thiantanawat A, Watcharasit P, Ruchirawat M, Satayavivad J (2016) Perfluorinated chemicals, PFOS and PFOA, enhance the estrogenic effects of 17beta-estradiol in T47D human breast cancer cells. J Appl Toxicol 36(6):790-801. doi:10.1002/ jat. 3210

Soule HD, Maloney TM, Wolman SR et al (1990) Isolation and characterization of a spontaneously immortalized human breast epithelial cell line, MCF-10. Cancer Res 50(18):6075-6086

Sundstrom M, Ehresman DJ, Bignert A et al (2011) A temporal trend study (1972-2008) of perfluorooctanesulfonate, perfluorohexanesulfonate, and perfluorooctanoate in pooled human milk samples from Stockholm, Sweden. Environ Int 37(1):178-183. doi:10.1016/j.envint.2010.08.014

van der Burg B, van Selm-Miltenburg AJ, de Laat SW, van Zoelen EJ (1989) Direct effects of estrogen on c-fos and c-myc 
protooncogene expression and cellular proliferation in human breast cancer cells. Mol Cell Endocrinol 64(2):223-228

Vidal A, Koff A (2000) Cell-cycle inhibitors: three families united by a common cause. Gene 247(1-2):1-15

Wang M, Chen J, Lin K et al (2011) Chronic zebrafish PFOS exposure alters sex ratio and maternal related effects in F1 offspring. Environ Toxicol Chem 30(9):2073-2080. doi:10.1002/etc.594
Wang J, Gildea JJ, Yue W (2013) Aromatase overexpression induces malignant changes in estrogen receptor alpha negative MCF-10A cells. Oncogene 32(44):5233-5240. doi:10.1038/onc.2012.558 